\title{
Laboratory Experiments of Drainage, Imbibition and Infiltration under Artificial Rainfall Characterized by Image Analysis Method and Numerical Simulations
}

\author{
Benjamin Belfort *(D), Sylvain Weill, Marwan Fahs ${ }^{\mathbb{D}}$ and François Lehmann \\ Université de Strasbourg, CNRS, ENGEES, LHYGES UMR 7517, F-67000 Strasbourg, France; \\ sylvain.weill@engees.unistra.fr (S.W.); fahs@unistra.fr (M.F.); lehmann@unistra.fr (F.L.) \\ * Correspondence: belfort@unistra.fr; Tel.: +33-368-850-386
}

Received: 26 September 2019; Accepted: 22 October 2019; Published: 25 October 2019

\begin{abstract}
Two laboratory experiments consisting of drainage/imbibition and rainfall were carried out to study flow in variably saturated porous media and to test the ability of a new measurement method. 2D maps of water content are obtained through a non-invasive image analysis method based on photographs. This method requires classical image analysis steps, i.e., normalization, filtering, background subtraction, scaling and calibration. The procedure was applied and validated for a large experimental tank of internal dimensions $180 \mathrm{~cm}$ long, $120 \mathrm{~cm}$ wide and $4 \mathrm{~cm}$ deep that had been homogenously packed with monodisperse quartz sand. The calibration curve relating water content and reflected light intensities was established during the main monitoring phase of each experiment, making this procedure very advantageous. Direct measurements carried out during the water flow experiments correspond to water content, pressure head, temperature, and cumulative outflow. Additionally, a great advantage of the proposed method is that it does not require any tracer or dye to be injected into the flow tank. The accuracy and other benefits of our approach were also assessed using numerical simulations with state-of-the-art computational code that solves Richards' equation.
\end{abstract}

Keywords: image processing; water content maps; unsaturated porous media; laboratory experiment; flow tank; drainage/imbibition; infiltration; artificial rainfall; 2D numerical simulations

\section{Introduction}

The vadose zone (VZ), situated between the soil surface and the groundwater table, supports many processes linked to the hydrological cycle. The dynamics of water in the VZ govern interrelationships between precipitation, surface runoff, infiltration, groundwater recharge and evapotranspiration [1-4]. The disciplines of soil physics, hydrology and agronomy study the VZ mainly through the lens of water flow and distribution. Furthermore, biological activities and transport phenomena are also affected by the specificities of this unsaturated part of the soil $[5,6]$. In other words, the VZ takes a central role within the critical zone extending from the vegetation canopy to the bottom of the groundwater aquifer, and as such, it is involved in many environmental and socio-economic issues.

Hence, the quantification of water dynamics in porous media is important to assess the effects of water management actions dealing with agricultural irrigation or water supply plans. The water content, and by extension the saturation of the media, is a key variable involved in the characterization and modelling of flow in the VZ. The relationships between pressure head, water content, and hydraulic conductivity have been widely studied with respect to the water retention curve or soil water characteristic curve $[7,8]$. Water content is also involved in the transport of solutes and pollutants (evaluation of pollution of groundwater reservoir, salinization, etc.), or in chemical reactions and 
interactions, because not all the void spaces are connected by water, contrary to what happens in ground water flow where the total porosity is taken into account [9]. Biological activity and development in porous media also depend on water content due to mobility-attachment effects, amount of dissolved oxygen (aerobic vs anaerobic zones), etc. [5,10].

Consequently, the measurement of water content is of great importance in many applications, both for research investigations and practical guidance. In recent decades, various technical solutions (neutron scattering techniques, gamma attenuation techniques, dielectric techniques, ground penetrating radar, optical techniques, etc.) and logistical supports (data-logger, geographic information system, etc.) have been developed, increasing our observation capacity [11-18]. The chosen and implemented devices can be distinguished in terms of accuracy, robustness, coverage, and volume of measurements, also taking into account their life cycle costs. In this context, the definition of scale for both the measuring and modelling issues remains a crucial point. According to Romano (2014) [14], the spatial scale of soil moisture observations/computations should be defined by the triplet of "support", "spacing", and "extent". As described by this author, the "support" is the volume in which the average value of soil moisture is obtained, "spacing" is the distance between the sensors, and "extent" represents the entire domain over which the measurements are carried out. The chosen technical solution determines the spatial resolution of the sensing probe and, consequently, the support of the measuring scale. In modelling issues, the spatial grid where the simulated outputs are computed represents the extent, which is the main information mentioned that deals with scale. Unfortunately, a mismatch in scale between observations and simulations often occurs (see [14]). The study depicted in this article focuses on an experimental system with external dimensions $203 \mathrm{~cm}$ long, $148 \mathrm{~cm}$ wide and $8 \mathrm{~cm}$ deep. The imaging technique applied allows the combination of local measurements with full photographs to provide 2D maps of water content that can be more efficiently compared to the simulated results.

Hence, in the present contribution, the domain of interest for water content measurement is the local scale. Usually, this means that the characteristic length of the soil volume investigated by the sensor probe ranges from about $0.10 \mathrm{~m}$ to $0.50 \mathrm{~m}$. Among the various methods available for measuring water content at the local spatial scale (see [14]), a distinction can be made between direct and indirect techniques. The thermo-gravimetric method, based on the difference between weight measurements before and after drying, is a direct, simple and inexpensive approach to access the water content. Nonetheless, it entails the destruction of the soil sample, and hence prevents the repetition of the measurement at the same location. With respect to indirect measurement methods, the most used techniques rely on neutron thermalization (gamma-ray attenuation or neutron scattering effects), dielectric-based sensing techniques, or other geophysical methods. When considering a substance subject to an electromagnetic field, its dielectric properties depend on the polarization of its molecules and are described by the apparent relative dielectric permittivity. Within the frequency range of roughly $50-100 \mathrm{MHz}$ to approximately $2 \mathrm{GHz}$, the water content of the soil sample can be correlated with the measured apparent relative dielectric permittivity of soil, which is principally affected by the apparent relative dielectric permittivity of water. Various techniques are traditionally used to access dielectric permittivity, including time domain transmissometry (TDT) or time domain reflectometry (TDR). Also, the capacitance and impedance techniques are used to estimate soil moisture [19-21]. Electromagnetic-based devices for the measurement of water content require calibration relationships that can be more or less suited depending on soil properties (compaction, organic matter, ... ) (see [22]). Nowadays, capacitance and impedance sensors are receiving more attention than TDR devices because of their lower price and required resources. Nonetheless, their accuracy and precision are much more prone to be affected by soil temperature and salinity variations. In the present article, impedance theta probes have been used; previous investigations [23] have given satisfactory results. Their size and technical specifications are appropriate to the dimensions of the domain and the local measurements expected from the experimental setup developed.

To get a profile or a map of water content without disturbing the flow domain, non-destructive measurement options have to be investigated. Non-invasive imaging techniques represent the most 
promising approach; they can carry out global observations leading to quantitative measurements without inserting (m)any probes in the porous media. Oostrom et al. (2007) [24], in their review, summarized different flow experiments and their associated qualitative/quantitative monitoring devices. In the context of hydrology, they focused particularly on (i) photon-attenuation-based methods, such as the gamma radiation method and the X-ray attenuation method, and (ii) photographic methods, such as the light reflection method (LRM), the light transmission method (LTM), and the multispectral image analysis method (MIAM). For our study, LRM was used because it can be conducted with non-transparent porous media and wide flow tanks; LTM is dedicated rather to transparent media of small dimensions, while MIAM is much more expensive to access saturation of different phases in porous media. Image analysis based on reflected light has largely been used for intermediate-scale experiments (e.g., [23,25-38]). Application of quantitative photometric procedures for unsaturated flow characterization is less widespread, and even less so with the LRM. The first application began with the LTM when Hoa (1981) [39] proposed a linear relationship between water content and the degree of illumination coming from an emergent light passing through a sand sample and collected by a photosensitive surface. Application of the LRM for characterizing flow dynamics in porous media was mainly restricted to qualitative observations, focusing for instance on the location of the water table. Then, Persson (2005) [40] and Yoshimoto et al. (2011) [41] directly measured the degree of saturation of an unsaturated porous medium with the LRM by relating variations in the color of the medium to water content changes. A feasibility study with small samples of different soil materials was proposed in the technical note of Persson (2005) [40]. Otherwise, Yoshimoto et al. (2011) [41] used a bright red food dye and disconnected calibration and experiments to achieve this goal. Belfort et al. (2017) [23] combined the advantages of these two approaches to determine water content, and Cremer et al. (2017) [42] have proposed an automatic image analysis that detects fingers in infiltration patterns and evaluates their width, velocity, and frequency. Hence, it is important to notice that the efficiency of optical measurement techniques to produce an accurate estimation of the variables of interest (i.e., saturation, concentration, etc.) relies on the quality of image processing. Therefore, the developed procedure has to account for data conversion, evaluation of the resolution size, selection of a sensitive channel, correction of brightness values for the LRM, and definition of a calibration curve. Concerning color specification, it could be defined either with traditional grey-scale values [34,43], or with red, green and blue (RGB) mean intensities [41]. Gerhard and Kueper (2003) [44] found that the best correlation with fluid saturation was obtained for the saturation component using the hue-saturation-brightness (HSB) system. Persson (2005) [40] adopted a linear combination of the saturation and value component of the hue-saturation-value (HSV) system; he also recommended the red channel for the RGB system. Finally, according to Konz et al. (2009) [27] and McNeil et al. (2006) [29], the green channel is the most sensitive for determining concentration; Belfort et al. (2017) [23] found the same result for water content. The majority of these studies used tracers or dyes to improve the visualization of processes using imaging techniques. For instance, Schincariol et al. (1990) [33] used Rhodamine WT liquid in their experiment on saltwater plumes, Konz et al. $(2008 ; 2009)[26,27]$ used Cochineal Red A (E124) and Cremer et al. (2017) [42] used Brilliant Blue dye. In the present study, we adopt the procedure proposed by [23] that characterizes the water content directly from the reflected light intensity of the media without any dye or tracer. The methodology includes, among other things, a normalization to avoid the effects of light fluctuations in contrast to Persson (2005) [40], and also a selection of the sensitive channel. The construction of the calibration curve is also directly derived from the experimental setup.

Several experimental studies dealing with variably saturated flow conditions have focused on issues such as water table recharge, the effects of capillary fringes, heterogeneity and anisotropy on the bench- or field scale (e.g., [38,45-52]). Other issues concern the estimation of unsaturated hydrodynamic parameters from column experiments, fingering and unstable flows observed during infiltration in dry unsaturated media, rainfall-induced slope failure, device calibration, flux quantification in VZ, etc. [42,53-57]. As previously stated, photography is currently used for qualitative explanations and observations because of evident visualization benefits; nonetheless, an advanced procedure might be 
required [42]. Our article focuses on the quantification of water content by photometric procedure, precisely where the neutron methods encountered difficulties due to the large size of the tank and where other methods could be much more invasive or disturbing.

Among the various motivations for developing numerical models in the domain of subsurface and groundwater flow, it should be noted that they are widely considered (i) as interpretative tools for investigating/understanding different involved processes and flow patterns, (ii) as predictive tools for testing different factors/conditions and assessing their impacts, (iii) as supporting tools for identifying practical solutions and planning the collection of field data, and (iv) as visualization tools for communicating key results. Checking simplification hypothesis and validating numerical models are of particular importance for the modelling community. This means that modelers have to verify if their numerical results are in agreement with the physics of the problem being examined, and subsequently if the mathematical and numerical approaches chosen are appropriate. To this end, analytical—numerical or experimental—benchmarking problems are performed and inter-comparisons carried out (for instance, [58,59]). Restricted access to the underground, punctual location of measuring devices with their own limited control volume, along with difficulties in porous media characterization, are significant drawbacks that induce the development of non-invasive procedures, among which the photometric procedure. Even if the goal of this paper is not to validate a new model for water flow in the VZ, we are convinced that numerical results have to be included to underline the benefit of the image analysis method.

Based on a previous article explaining how to construct 2D maps of water content from photometric images and the originalities of the method (see [23]), this article aims (i) to apply and test this procedure on a larger experimental tank with different experimental boundary conditions including drainage, infiltration under artificial rainfall, and imbibition, and (ii) to compare observation-deduced maps with numerical results based on Richards' model for VZ flow.

\section{Materials and Methods}

\subsection{The 2D Flow Tank and Porous Media}

The original flow visualization experiments are conducted in a rectangular flow tank of external dimensions $203 \mathrm{~cm}$ long, $148 \mathrm{~cm}$ wide, and $8 \mathrm{~cm}$ deep. The back, lateral and bottom walls consist of 2-cm-thick polycarbonate sheets to give more rigidity and the front side is fabricated in a 2-cm-thick transparent sheet of Plexiglas for facilitating visual observation of moisture changes. The flow tank is divided into three distinct chambers: a central flow chamber containing the porous medium and two lateral chambers $\left(20 \mathrm{~cm}^{2} \times 120 \mathrm{~cm}\right)$ containing freshwater and connected to outflow systems for controlling the application of boundary conditions. The internal dimensions of the porous media region are approximatively $180 \mathrm{~cm} \times 120 \mathrm{~cm} \times 4 \mathrm{~cm}(\mathrm{~L} \times \mathrm{W} \times \mathrm{D})$. The partitioning between chambers is realized with a device of polycarbonate blocks which are variably perforated to simulate different levels of water imposed at the boundaries depending on the performed experiments. O-rings embedded in the side rails provide a seal with forces applied by clamping screws distributed along the length and height of the chambers. Two external aluminum stiffening bars are placed vertically in the middle of the flow chamber in order to minimize bending of the Plexiglas wall under the pressures exerted by sand and water (see Figure 1). At the top, two removable shells are added to maintain a constant spacing of the flow chamber without impeding the filling of the tank. The back wall is drilled with many sensor ports that can be used depending on the experimental setup. The tank has also five openings at the bottom, which are regulated by valves. An opening placed under each lateral chamber is connected to an overflow outlet whose height can be adjusted as required. All openings, at the bottom side and on the lateral separation bars, are covered with a nylon filter mesh to avoid sand discharge as water leaves the tank. 


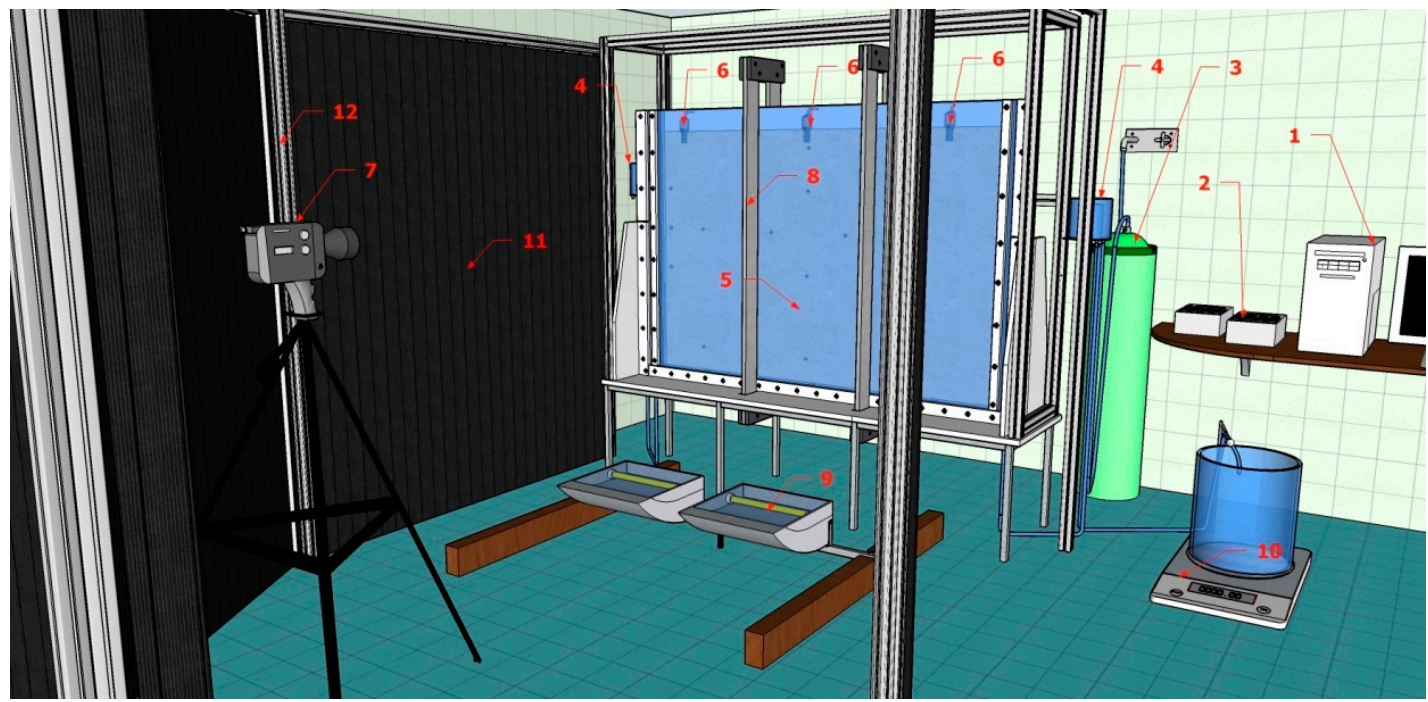

Figure 1. Schematic representation of the experimental setup: (1) computer (softwares: Keysight VEE, ImageJ, Nikon Camera Control); (2) data logger; (3) water purification system (Veolia-Aquadem); (4) 2 overflow outlets (can be moved along the vertical axis); (5) Plexiglas flow tank $(180 \mathrm{~cm} \times 120 \mathrm{~cm} \times 4 \mathrm{~cm})$; (6) 3 theta probes ML2x; (7) NIKON digital camera D80; (8) aluminum stiffening bars; (9) floodlight (400 W); (10) Sartorius digital balance; (11) black curtain (all around the experiment); (12) Norcan metallic structure).

The tank is homogenously packed, as far as possible, with monodisperse quartz sand (reference K30, from Kaltenhouse, France). The filling of the flow chamber is achieved in layers of a few millimeters at a time by using a system composed of a funnel and PVC tubes. Overflow outlets are progressively moved higher up to allow more water than sand in the tank, in order to avoid the trapping of air. A rod is also used to ensure that the medium is well placed and is tapped gently with a piece of PVC to produce the most uniform compaction.

Hence, the material surrounding the flow tank is comprised of a digital balance with a weighing capacity of $34 \mathrm{~kg}$ and a readability of $0.1 \mathrm{~g}$, two light devices placed horizontally at the bottom front of the tank, and an opaque black curtain that is arranged around the tank and the camera. Notice that two white cards (with dimensions of around $7.5 \mathrm{~cm} \times 14.5 \mathrm{~cm}$ ) have been attached to the front face of the tank for the purposes of normalization, i.e., to correct possible fluctuations in lighting.

\subsection{Image Acquisition and Instruments Used to Take Direct Measurements}

A Nikon digital camera D80, placed on a fixed metal tripod at a distance of approximately 3 meters from the tank, automatically records the images in the raw format (unprocessed files ".nef"). All camera parameters (ISO100, shutter speed 1/6 s, aperture F11.0) are set manually to take large-sized images with dimensions of 3872 pixels wide by 2592 pixels high. The acquisition device is kept as uniform as possible throughout the duration of the experiment because of the requirements of image processing, primarily pixel-by-pixel intensity tracking at different times.

Direct measurements carried out during the water flow experiments consist of water content, pressure head, temperature, and cumulative outflow. Pressure transmitters used (PR-41X/81955, Keller Druckmesstechnick) are floating piezo resistive transducers, and measure pressure head from -0.1 to 0.1 bar with $\pm 0.2 \%$ FS (full scale) accuracy. To ensure good transmission of pressure and suction, a small porous ceramic cup (of $6 \mathrm{~mm}$ diameter and $28 \mathrm{~mm}$ length) is inserted into the porous media and attached to a Plexiglas tube filled with deionized de-aired water which is connected to each pressure device. After having completely removed air bubbles, the device with ceramic cups may remain saturated up to a pressure of less than $0.1 \mathrm{MPa}$ (or $1 \mathrm{~atm}$ ). 
Water content is measured using three theta probes, Type ML2x (Delta-T Devices Ltd.). This kind of sensor is based on medium impedance measurements [60]. The soil probe consists of four inert metal electrodes that are $6 \mathrm{~cm}$ in length and are inserted vertically into the surface of the porous media. The soil sampling volume indicated by the manufacturer consists of a cylinder $4 \mathrm{~cm}$ in diameter by $6 \mathrm{~cm}$ in length (for a volume of approximately $75 \mathrm{~cm}^{3}$ ) surrounding the central rod. For a range of measurements between 0.05 and $0.6 \mathrm{~m}^{3} \mathrm{~m}^{-3}$, the accuracy reaches $\pm 0.01 \mathrm{~m}^{3} \cdot \mathrm{m}^{-3}$. The theta probe was calibrated through column experiments that used different sand/water mixtures prepared over the whole range of water content values (from 0 to $\theta_{\mathrm{s}}$ with a step of 0.05 ).

Details on the positioning of the pressure and water content sensors, with plans and photographs, are provided in Figures S1 and S2 of the Supplementary Materials.

\subsection{Method Dealing with Photometric Procedure}

The photometric procedure for obtaining water content maps is fully described in a previous article [23], and the present section summarizes the main steps automatically performed by the program:

- Importing the images, converting to 16-bit .tiff images and extracting their information.

- Selecting the color space (global, RGB or HSB image stacking).

- Applying a median filter with a radius value of 5 . The intensity of the pixel located at position $(x, z)$ on the picture taken at time $t$ as $I(x, z, t)$.

- Normalizing the pre-processed image to get $I_{c o r}(x, z, t)$. The minimum and maximum intensity values $\left(I_{\min }(t)\right.$ and $\left.I_{\max }(t)\right)$ are measured for each picture and allow us to normalize the picture according to the following equation:

$$
I_{c o r}(x, z, t)=\left[I(x, z, t)-I_{\min }(t)\right] /\left[I_{\max }(t)-I_{\min }(t)\right]
$$

- Obtaining $I_{p r o c}(x, z, t)$ through background subtraction:

$$
I_{p r o c}(x, z, t)=I_{c o r}(x, z, t)-I_{c o r}(x, z, 0)
$$

- Obtaining $I_{p r o c, a v}(t)$ through the insertion of a measurement zone.

A rectangular zone is inserted that corresponds to the projected soil sampling volume of the Theta probe sensor on the front pane; its physical dimensions, $4 \mathrm{~cm} \times 6 \mathrm{~cm}$, represent 87 pixels $\times 129$ pixels on the picture. Circles of 11 px diameter (almost $0.5 \mathrm{~cm}$, i.e., the dimension matching the influence diameter of a ceramic porous cup) can also be inserted at the positions where pressure heads are monitored. Average intensities are automatically computed and stored in the results output file.

- Obtaining $\theta_{i m g}(x, z, t)$ through image calibration:

$$
\theta_{\text {img }}(x, z, t)=a+b \times I_{p r o c}(x, z, t)
$$

- Converting processed intensities to water contents to construct moisture maps.

- Computing the error of the estimated water content:

$$
\hat{\theta}-t_{0.16} \times s(\hat{\theta})<\hat{\theta}<\hat{\theta}+t_{0.16} \times s(\hat{\theta})
$$

In Equation (4), $t_{0.16} \simeq 1.0$ is given by the Student distribution with $(\mathrm{Nm}-2)$ degrees of freedom for a confidence interval of $68 \%$.

The error of the estimated water content is composed of a calibration component $s_{\mathrm{Cal}}{ }^{2}(\hat{\theta})$ and an instrumental component $\operatorname{sinst}^{2}(\hat{\theta})$ and can be expressed as follows:

$$
s^{2}(\hat{\theta})=s_{C a l}{ }^{2}(\hat{\theta})+s_{\text {Inst }}^{2}(\hat{\theta})
$$




$$
\begin{aligned}
s_{C a l}(\hat{\theta})= & s^{2}(e)+s^{2}(\hat{a})+\hat{I}^{2} \times s^{2}(\hat{b})+2 \times \hat{I} \times s(\hat{a}, \hat{b}) \\
& s_{\text {Inst }}{ }^{2}(\hat{\theta})=\left[\hat{b}^{2}-s^{2}(\hat{b})\right] \times s^{2}(\hat{I})
\end{aligned}
$$

where $N m$ is the number of pairs $(\hat{I}, \hat{\theta})$ used for the correlation, $s^{2}(e)$ is the disturbance variance, $s^{2}(\hat{a})$ and $s^{2}(\hat{b})$ are the estimated variances of $\hat{a}$ and $\hat{b}$, respectively, $s(\hat{b}, \hat{a})$ is the estimated covariance between $\hat{a}$ and $\hat{b}$ (see [23]).

\subsection{Numerical Method for Variably Saturated Flow Modelling}

Richards' equation (RE, see Equation (8)) is used to model variably saturated flow in porous media. This means that the flow velocity is estimated using Darcy-Buckingham's law, i.e., assuming that air remains at atmospheric pressure.

$$
\frac{\partial \theta}{\partial t}+S_{S} S_{W} \frac{\partial h}{\partial t}+\nabla \cdot(-K(h) \cdot \nabla H)=f
$$

In the mixed form of RE given above, $H(\mathrm{~L})$ and $h(\mathrm{~L})$ are the hydraulic piezometric and pressure heads, respectively, such that $H=h+z ; z(\mathrm{~L})$ is the elevation, which is taken to be positive upward; $S_{S}\left(\mathrm{~L}^{-1}\right)$ is the specific storage; $S_{W}(-)$ is the relative saturation of the aqueous phase $\left(S_{w}(h)=\theta(h) / \theta_{S}\right)$; $\theta(h)\left(\mathrm{L}^{3} \mathrm{~L}^{-3}\right)$ and $\theta_{s}\left(\mathrm{~L}^{3} \mathrm{~L}^{-3}\right)$ are the actual and saturated water contents, respectively, $K(h)\left(\mathrm{LT}^{-1}\right)$ is the hydraulic conductivity as a function of pressure head; and $f\left(\mathrm{~T}^{-1}\right)$ is the source-sink term.

The model description is completed by relationships relating water content and hydraulic conductivity to pressure head. The standard Mualem-van Genuchten (1980) [61] models are used here for the pressure-saturation and conductivity-saturation relationships:

$$
\begin{gathered}
S_{e}=\frac{\theta-\theta_{r}}{\theta_{S}-\theta_{r}}=\left\{\begin{array}{cc}
\frac{1}{\left(1+(\alpha|h|)^{n}\right)^{1-1 / n}} & h<0 \\
1 & h \geq 0
\end{array}\right. \\
K\left(S_{e}\right)=K_{S} \times K_{r}(h)=K_{S} \times S_{e}^{1 / 2}\left(1-\left[1-S_{e} \frac{n}{n-1}\right]^{1-\frac{1}{n}}\right)^{2}
\end{gathered}
$$

in which $S_{e}$ is the effective saturation $(-), \theta_{r}$ is the residual water content $\left(\mathrm{L}^{3} \mathrm{~L}^{-3}\right), \alpha$ is a parameter related to the mean pore size, $n$ is a parameter reflecting the uniformity of the pore size distribution, $K_{s}$ is the saturated conductivity and $K_{r}$ is the relative conductivity, and $n>1$. Parameters can be obtained by inverse modelling (see [53]). In addition to the hydraulic parameters characterizing the porous medium $\left(K_{S}, \theta_{S}, \theta_{r}, \alpha, n, S_{S}\right)$, numerical solution of the mathematical model (Equations (8), (9) and (10)) requires the definition of initial and boundary conditions (at the surface, bottom and lateral parts of the flow chamber) characterizing the problem studied. In terms of initial conditions, the fully saturated condition is required for the calibration procedure. Full details of the numerical methods can be found in previous research articles [62,63]. Concerning the discretization, an unstructured mesh composed of 11,154 triangles is used for both experiments; this means that the domain is represented by triangular cells of about $2 \mathrm{~cm}^{2}$.

\section{Results and Discussion}

\subsection{First Experiment: Simple Drainage-Imbibition Cycle}

The first flow experiment consisted of a single drainage-imbibition cycle. It was carried out over 3.75 days. The flow chamber was initially fully saturated, and the water level was adjusted with overflow outlets so that no ponding conditions were encountered at the surface. To avoid modification of the porous media arrangement in the experimental tank during the experiment, which could affect the results mainly due to background subtraction, three complete imbibition-drainage cycles were carried out over the previous few weeks. Initial conditions were maintained for 3 hours after the 
beginning of image acquisition and sensor monitoring. The drainage phase consisted of ten successive steps, followed by ten successive steps of imbibition; each step was characterized by a displacement of the right overflow outlet by $10 \mathrm{~cm}$ (see Table 1) and a duration of 3 to 6 hours. The evolution of the lateral boundary condition during the experiment is imposed with the right overflow outlet (relative to the clear Plexiglas front pane), whereas the left outlet is kept in place to conserve the reference of the top water level. Two pressure sensors were connected to valves above the lateral chambers in order to record the level of water on each side of the flow chamber. In this manner, the real boundary condition encountered in our laboratory experiment could be set in the numerical model. The evolution of water in the right and left lateral chambers as a consequence of the overflow outlet displacement is depicted in Figure 2.

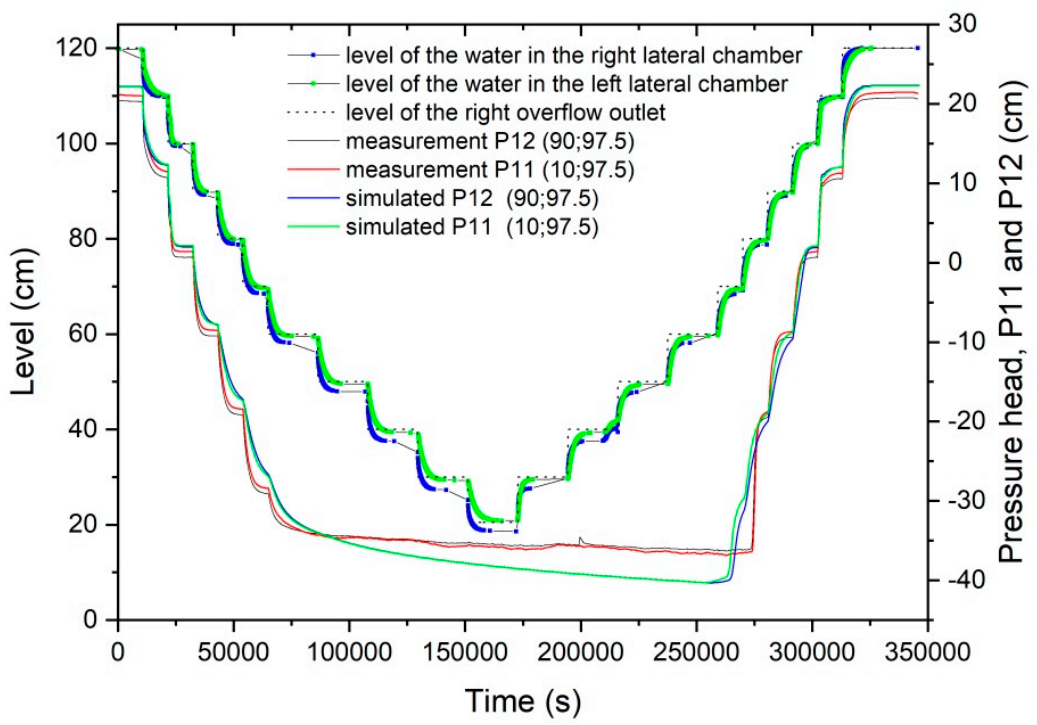

Figure 2. First experiment: position of the right overflow outlet (dotted black line) and consequence on the level of water monitored in the right lateral (solid black line with blue square symbols) and left lateral (solid black line with green square symbols) chambers. Evolution of measured pressure head $(\mathrm{P} 11 \mathrm{x}=10 \mathrm{~cm} / \mathrm{z}=97.5 \mathrm{~cm}$ : solid red line, $\mathrm{P} 12 \mathrm{x}=90 \mathrm{~cm} / \mathrm{z}=97.5 \mathrm{~cm}$ : solid black line $)$ and simulated values (P11: solid green line, P12: solid blue line).

The correction of fluctuations in brightness is of great importance, and Figure 3 illustrates the necessity of this step. In fact, Figure 3a shows the evolution of raw intensities over the course of the experiment. The standard deviations of the two series corresponding to the right and the left white cards are greater than 300 . The fluctuations occurring could be linked to the stability of the electrical power supply which is affected differently during nights and days because of activities in the building. In Figure 3b, Equation (1) is used to normalize the raw intensities. The images are on the same intensity level and standard deviations are limited to $4.93 .10^{-4}$, suggesting that the correction method works well. 
Table 1. Experimental procedure: movement of the overflow outlet responsible of transient flow in the flow chamber.

\begin{tabular}{|c|c|c|c|c|c|c|c|c|c|c|c|c|c|c|c|c|c|c|c|c|}
\hline \multicolumn{21}{|c|}{ 1st Experiment: Simple Drainage-Imbibition Cycle } \\
\hline $\begin{array}{l}\text { Right overflow outlet } \\
\text { displacement }(\mathrm{cm})\end{array}$ & -10 & -10 & -10 & -10 & -10 & -10 & -10 & -10 & -10 & -9.5 & 9.5 & 10 & 10 & 10 & 10 & 10 & 10 & 10 & 10 & 10 \\
\hline step duration $(\mathrm{h})$ & 3 & 3 & 3 & 3 & 3 & 6 & 6 & 6 & 6 & 6 & 6 & 6 & 6 & 6 & 3 & 3 & 3 & 3 & 3 & 3 \\
\hline $\begin{array}{l}\text { Elapsed time at the end } \\
\text { of the step }(\mathrm{h})\end{array}$ & 6 & 9 & 12 & 15 & 18 & 24 & 30 & 36 & 42 & 48 & 54 & 60 & 66 & 72 & 75 & 78 & 81 & 84 & 87 & 90 \\
\hline \multicolumn{21}{|c|}{ 2nd experiment: drainage-rainfall-drainage-imbibition cycle } \\
\hline description & $\begin{array}{l}\text { Waiting } \\
\text { time }\end{array}$ & \multicolumn{4}{|c|}{$\begin{array}{c}\text { Both overflow outlets } \\
\text { displacement }(\mathrm{cm})\end{array}$} & Cons & ant rai & nfall & Wa & iting tin & & \multicolumn{7}{|c|}{ Both overflow outlets displacement (cm) } & & \\
\hline details & $\begin{array}{c}\text { fully } \\
\text { saturated }\end{array}$ & \multicolumn{2}{|c|}{-50} & \multicolumn{2}{|c|}{-48.5} & & - & & \multicolumn{3}{|c|}{ Partially saturated } & \multicolumn{3}{|c|}{48.5} & \multicolumn{3}{|c|}{49} & 1 & & \\
\hline step duration $(\mathrm{h})$ & 1.5 & \multicolumn{2}{|c|}{5} & \multicolumn{2}{|c|}{17} & & 7 & & \multicolumn{3}{|c|}{41} & \multicolumn{3}{|c|}{5} & \multicolumn{3}{|c|}{4} & \multicolumn{2}{|l|}{1} & \\
\hline $\begin{array}{l}\text { Elapsed time at the end } \\
\text { of the step (h) }\end{array}$ & 1.5 & \multicolumn{2}{|c|}{6.5} & \multicolumn{2}{|c|}{23.5} & \multicolumn{3}{|c|}{30.5} & \multicolumn{3}{|c|}{71.5} & \multicolumn{3}{|c|}{76.5} & \multicolumn{3}{|c|}{80.5} & \multicolumn{2}{|l|}{81.5} & \\
\hline
\end{tabular}



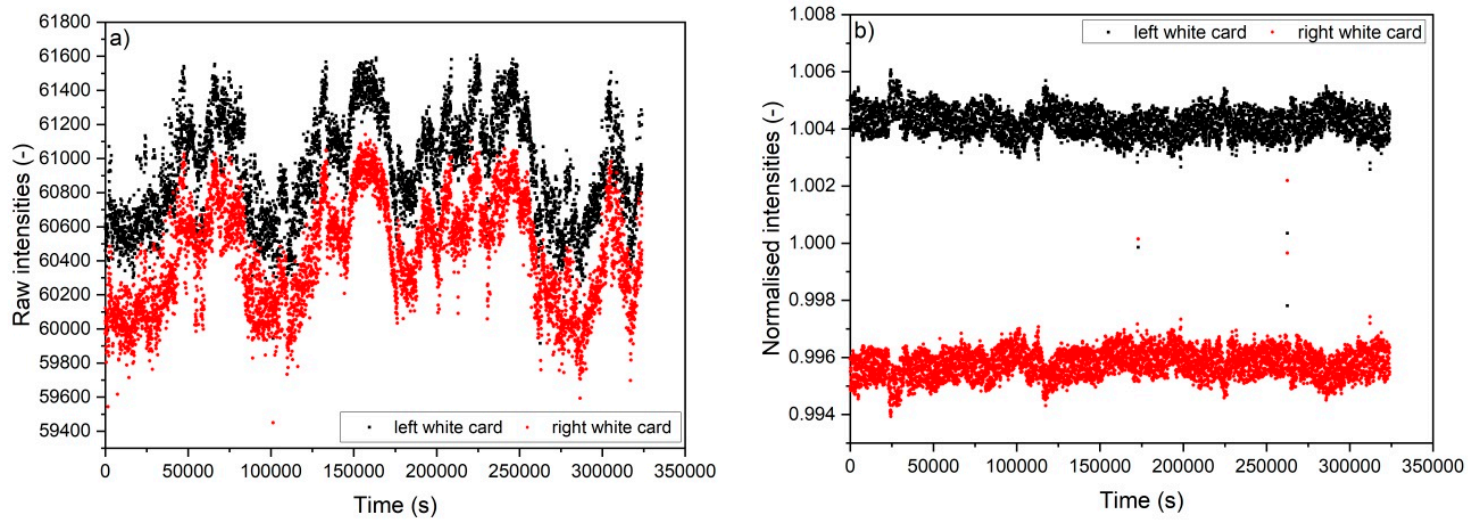

Figure 3. Evolution of the raw intensities (a) and normalized intensities (b) of white cards during the complete experiment (Green channel).

In basic image processing steps, filtering is generally applied to reduce random superimposed variations and impulse noise, for instance coming from grain size in a photograph. In this view, "Kernel" operations are generally employed to accomplish neighborhood averaging or ranking on pixel values (see [64]). The median filter consists of replacing a pixel value by the median value of a selected neighborhood pattern. The median smoothing technique is used in studies dealing with contaminant hydrology or porous media characterization, mainly with radii from 1 to 3 pixels (i.e., from $3 \times 3$ - to $7 \times 7$-pixel squares) $[29,34,65,66]$. Nonetheless, filtering techniques are sometimes counter indicated, because they can have a negative effect on the sharp edges, i.e., they introduce diffusion, which affects the resolution and the identification of edges $[67,68]$. In the section devoted to the large flow tank, filtering steps have not been included, mainly because of the larger pixel size. The correction of imaging defects can be linked to the issue of measurement area, which has been considered to a moderate extent in the literature. In [26], the concentration at a point is given by the median of 100 pixels, which corresponds to a surface of $31 \mathrm{~mm}^{2}$. [41] considered horizontal samples to determine that the luminance value is stable for a surface of $200 \times 200$ pixels, i.e., a zone measuring about $1 \mathrm{~cm}^{2}$. Hence, for our experiment, we determined the measurement area following the same approach as [26]. Squares of 108 pixels in length (around $5 \mathrm{~cm} \times 5 \mathrm{~cm}$ ) at different locations were considered, and the processed intensities of the 11,664 pixels were stored. Non-corrected pixel values and median smoothing values of radius 1 to 19 px were investigated in order to identify the reasonable definition of the maps that will be compared to modelling results.

In the case of vertical unsaturated water flow, it is difficult to isolate the impact of the optical heterogeneity of porous media. This might be done easily at the beginning or at the end of the experiment with a fully saturated condition in the tank, or when the upper part of the central flow chamber is not submitted to transient flow. Tests were carried out with raw images, normalized and processed intensities at different locations of the tank, and at different times to analyze the optical heterogeneity of porous media.

Therefore, Figure 4a illustrates the results in the left upper part of the flow chamber, in a square of $25 \mathrm{~cm}^{2}$ (11,664 pixels), after a long time of drainage (72 h), allowing consideration of a stabilized condition in the tank. Note that imbibition steps begin without affecting the observation point. The effect of median smoothing clearly appears in Figure 4a, which depicts the 11,664 pixel values derived from $1 \times 1$ pixel and the median over $5 \times 5,11 \times 11$ and $39 \times 39$ pixels. The fluctuation of intensities increases with increasing resolution. The comparison of $95 \%$ confidence intervals in Figure $4 \mathrm{~b}$ shows that the dispersion of results decreases with increasing radius of median smoothing. The purpose of this picture is to identify possible dimensions for the size of the measurement area. A length of around $0.7 \mathrm{~cm}$ (radius $=7$, corresponding to an area of about $48 \mathrm{~mm}^{2}$ and a $95 \%$ confidential interval less than $1.0 \times 10-5$ ) should be the critical minimal size to respect. According to the tests performed at different times and locations, the resolution for the water content maps is based on a 
unit length of $1 \mathrm{~cm}$; this means that each image is decomposed into a grid with a square mesh size of $1 \mathrm{~cm} \times 1 \mathrm{~cm}$ and each cell returns the median value of its interior pixels. These results are in good agreement with previous recommendations by [26] and [41]. Consequently, for both kinds of sensor, pressure transmitters, and water probes, the soil sampling volumes are above this critical size.
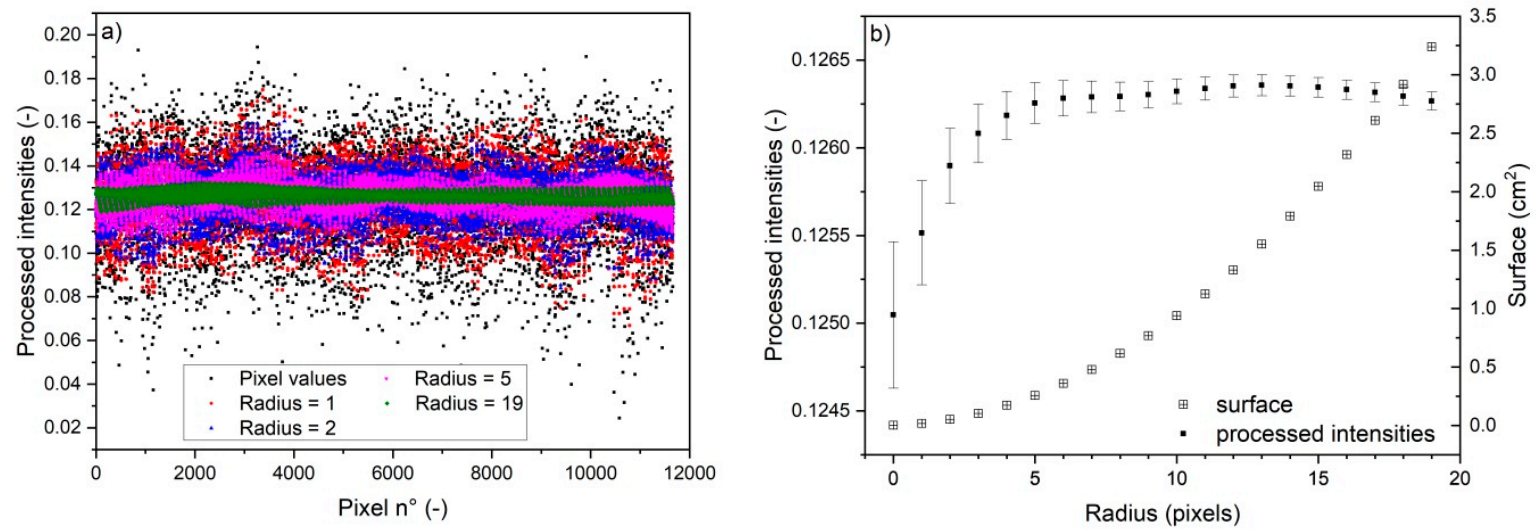

Figure 4. Representation of intensities after $72 \mathrm{~h}$ in the left upper side of the flow chamber: (a) intensities of the 11,664 pixels of a $5 \times 5 \mathrm{~cm}^{2}$ square for pixel unity and derived as median of squares of $1 \mathrm{px}$, 2 px, 5 px and 19 px radius. (b) Solid black square symbols depict the mean of the pixel and median values (median smoothing with radius from 1 to $19 \mathrm{px}$ ) and attached error bars represent $95 \%$ confidence interval. Curve with empty square symbols with plus center shows the corresponding area of measurement (right axis of the graphic).

The calibration curve between light intensity and water content was constructed with 21 images referring to the state at the end of each flow step in order to avoid transient flow (cf. Table 1). Since three theta probes were monitored, a total of $N_{m}=63$ points are depicted in Figure 5. For each point of the calibration curve, the error in the processed intensities was computed by considering the 10 images recorded during the 10 minutes before each flow step. Hence, error bars have been depicted in Figure 5. As prescribed in the final step of the procedure, a linear regression is performed and the fitting coefficients corresponding to Equation (3), computed for the entire range of points is presented in Table 2.

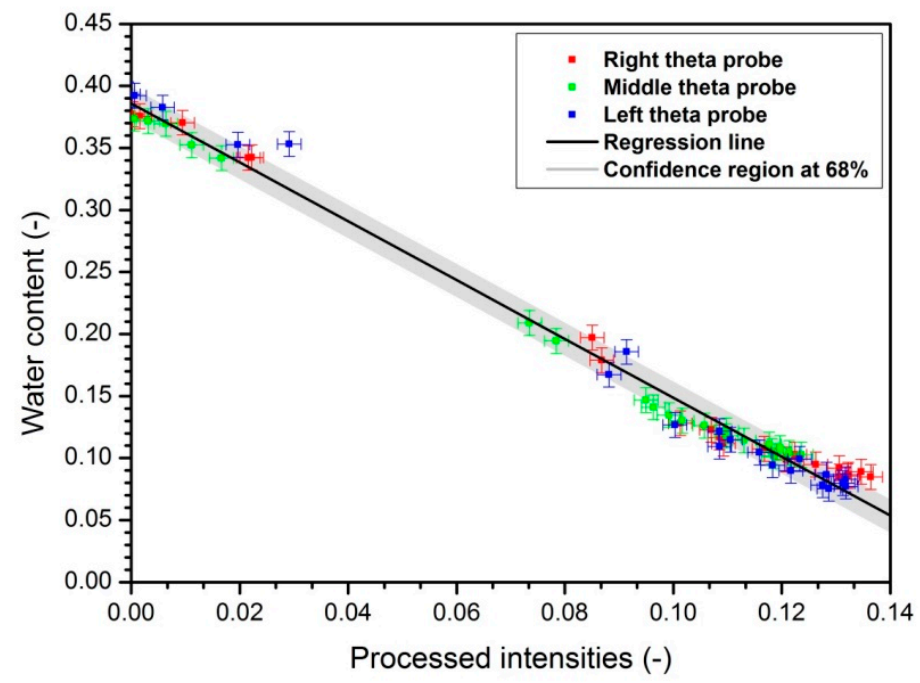

Figure 5. Intensity vs. water content calibration plot of the three theta probes installed at the surface of the large flow tank (red, blue and green marks); regression line (solid black line) and confidence intervals at $68 \%$ (grey zone). The horizontal and vertical bars correspond to the maximal measurement error on $(\hat{I}, \hat{\theta})$ estimated to \pm one standard deviation. 
Table 2. Calibration parameters and statistics of linear regression.

\begin{tabular}{ccc}
\hline Parameter & Value & Standard Error \\
\hline$\hat{a}$ & 0.3859 & 0.003 \\
\hline$\hat{b}$ & -2.373 & 0.031 \\
\hline $\mathrm{r}^{2}$ & 0.989 & \\
\hline$s(\hat{a}, \hat{b})$ & $-8.67410^{-5}$ & \\
\hline$s^{2}(e)$ & 0.00013 & 0.01151 \\
\hline$s^{2}(\hat{I})$ & $4.7710^{-6}$ & 0.002184 \\
\hline
\end{tabular}

Figure 5 also depicts the results of error analysis. The errors $s^{2}(\hat{\theta})$ and $s^{2}(\hat{I})$ in water content (vertical error bars) and proceeded intensity (horizontal error bars) respectively, were reported for each point used in the estimation of the calibration curve; the different coefficients and error values are reported in Table 2. The 68\% confidence region, computed with Equation (4), is also shown in Figure 5. As can be also noticed with the high value of the r-squared coefficient $\left(r^{2}\right.$ in Table 2$)$, these elements indicate a good fit between measurements and confirm the linear regression model used. To conclude this part, we have to indicate that the calibration component, $s_{\mathrm{Cal}}{ }^{2}(\hat{\theta})$ in Equation (6), is the largest component of the total variance of water content values and it is mainly explained by the error in the residual disturbance term $s^{2}(e)$ and $s^{2}(\hat{a})$. These results, obtained on a larger scale and with more sensors, are in agreement with those of [23].

We look at the error in water content at specific locations. Figure 6 depicts the evolution of water content during the drainage imbibition experiment for the three theta probe sensors. The photometric procedure is applied in the corresponding zones and the evolution of computed water content is also shown. Then, absolute and relative errors over time are calculated as follows:

$$
\begin{gathered}
\theta-\operatorname{AbsErr}_{\text {cum }}(j)=\frac{\sum_{i=1}^{j}\left|\theta_{\text {cal }, i}-\theta_{\text {mes }, i}\right|}{\sum_{k=1}^{j \max } \theta_{\text {mes }, k}} \times 100 \\
\theta-\operatorname{Re} \operatorname{Lrr}_{\text {cum }}(j)=\frac{\sum_{i=1}^{j}\left(\theta_{\text {cal }, i}-\theta_{\text {mes }, i}\right)}{\sum_{k=1}^{j \max } \theta_{\text {mes }, k}} \times 100
\end{gathered}
$$

where $\mathrm{j}$ refers to desired printing time (between 1 and jmax $=5399$; total duration is $90 \mathrm{~h}$ ), $\mathrm{i}$ corresponds to the different dates of the photographs (in fact each minute), $\theta_{\text {mes }}$ is the measured water content, and $\theta_{\text {cal }}$ is the value obtained with the photometric procedure on the $4 \times 6 \mathrm{~cm}^{2}$ zone corresponding to the sensor location. Absolute and relative cumulative errors are shown in Figure 7 . The linear trend of the cumulative error curves until 2.3 days indicates a relatively constant error; after 200,000 seconds, i.e., during the imbibition phase, the error of sensor 3 (and to a lesser extent that of sensor 1 ) increases. An explanation can be found in the water supply, which is achieved with a single overflow outlet giving a true 2D process in the tank. Figure 7 shows that the water content obtained from photographs is overestimated during drainage and underestimated during imbibition, which is in concordance with previous results obtained with the photometric method [23]. 


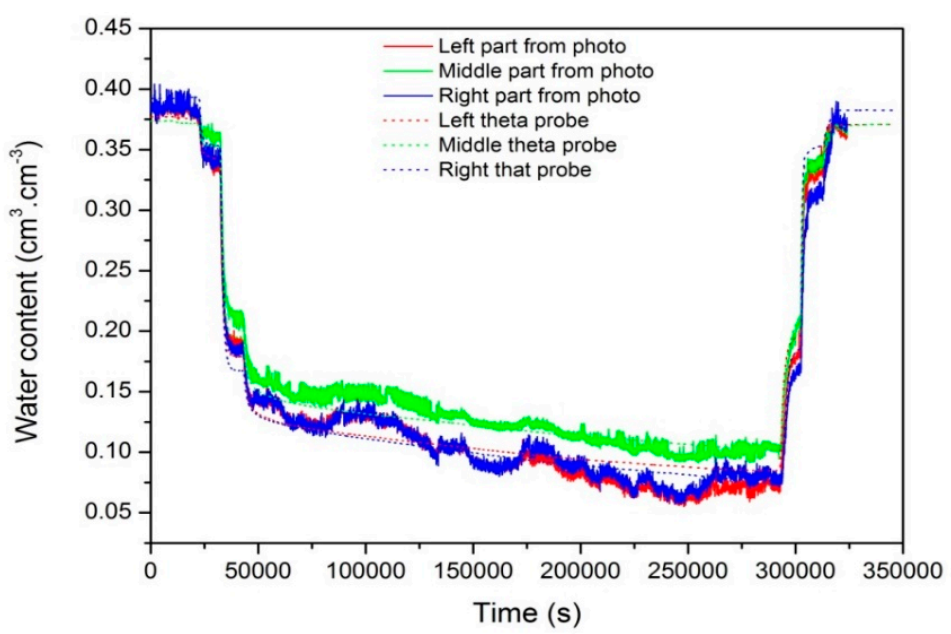

Figure 6. Evolution of the water content in the large flow tank: comparison of the 3 measurements (dotted lines) and results of the photometric procedure (solid lines).

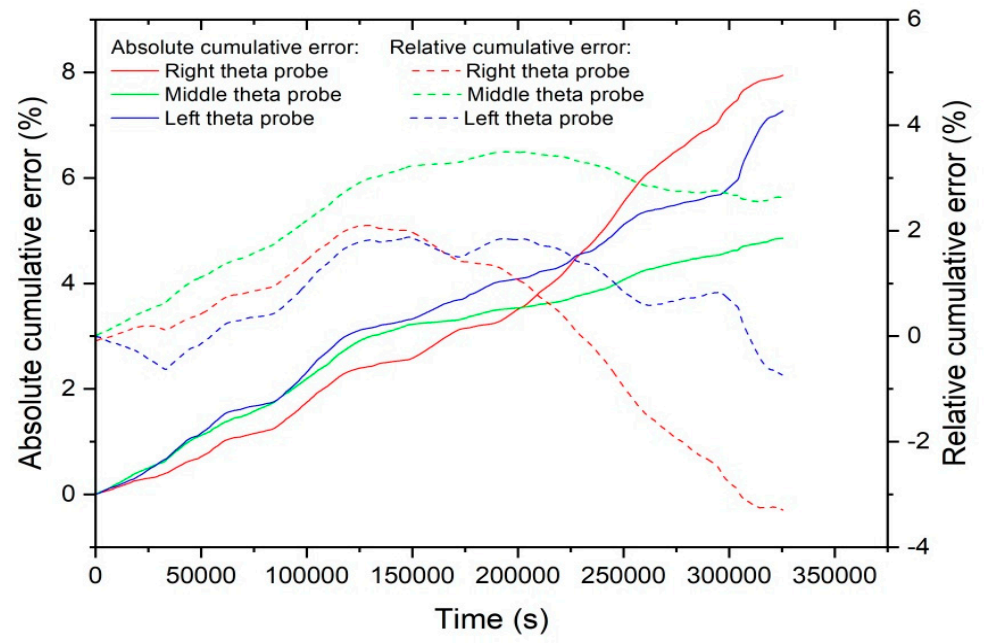

Figure 7. Evolution of cumulative error in water content in the large flow tank: absolute (solid lines, computed with Equation (11)) and relative (dashed lines, computed with Equation (12)) errors between measurements and computation.

The measurement of cumulative outflow mass was performed with a digital balance, even if, for this large flow tank experiment, the measurement was subject to more technical difficulties (presence of lateral chambers, length of pipes, etc.). Figure 8 depicts the mass balance measurements during the drainage steps, the cumulative mass obtained from photographs throughout the complete experiment, and the theoretical calculation at the end of each step. The contributions of the lateral chambers and the fixed overflow outlet are taken into account to correct the results of the theoretical and photographic methods. A good agreement was obtained with the knowledge that the error is amplified by the 3D computation of the cumulative mass. As previously stated, the water content coming from the photometric procedure is overestimated during drainage and the error on the cumulative mass does not exceed $3 \mathrm{~kg}$, which is less than $12 \%$. Figure 9 depicts water content profiles at different times during drainage for both the photometric procedure and numerical simulation. Notice that for the first experiment, we considered that the soil material may be described by the following parameter values: $K_{s}=5.10^{-3} \mathrm{~cm} . \mathrm{s}^{-1}, \theta_{s}=0.375, \theta_{r}=0.099, \alpha=0.04 \mathrm{~cm}^{-1}, n=7.45$ and $S_{S}=1.10^{-10} \mathrm{~cm}^{-1}$ (values corresponding to Sim1 in [23]). The general trends are similar, except that the photometric procedure is able to capture the sharpness of the infiltration front, while numerical modelling would require better parameter estimation. The evolution of pressure heads simulated and measured at two specific 
control points located near the surface of the flow tank is represented in Figure 2. Again, it shows that differences between local measurements and numerical results can be observed, but that the trend is globally well reproduced. Hence, comparing Figures 2 and 10 underlines that photographs are of great interest in following the elevation of the water table and especially the dynamic of the experiment in the vadose zone from a spatial and temporal point of view.

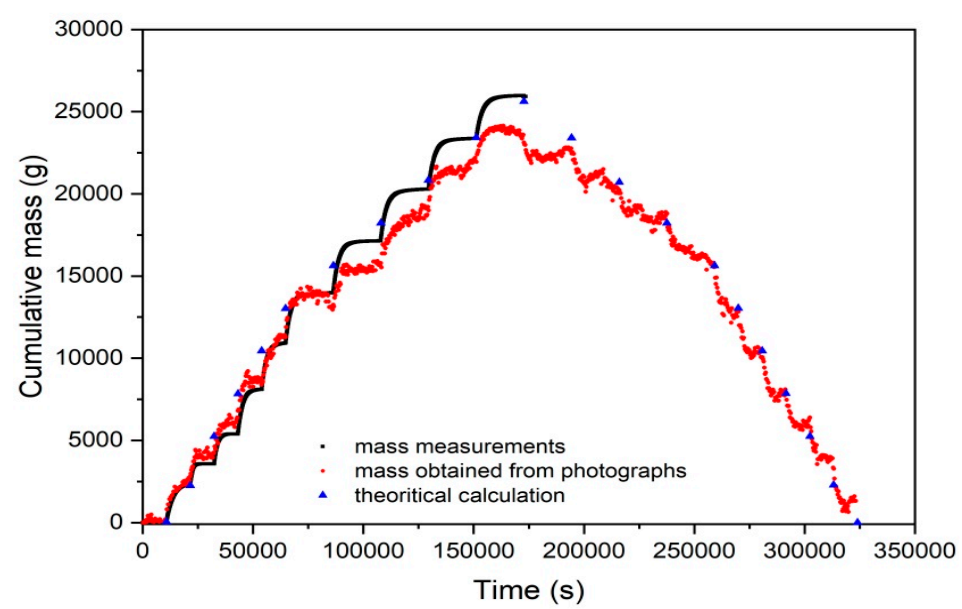

Figure 8. Evolution of the cumulative mass leaving and entering the flow tank: comparison between mass measurements (black square symbols), values obtained from photometric procedure (red circle symbols), and theoretical values (blue triangular symbols).

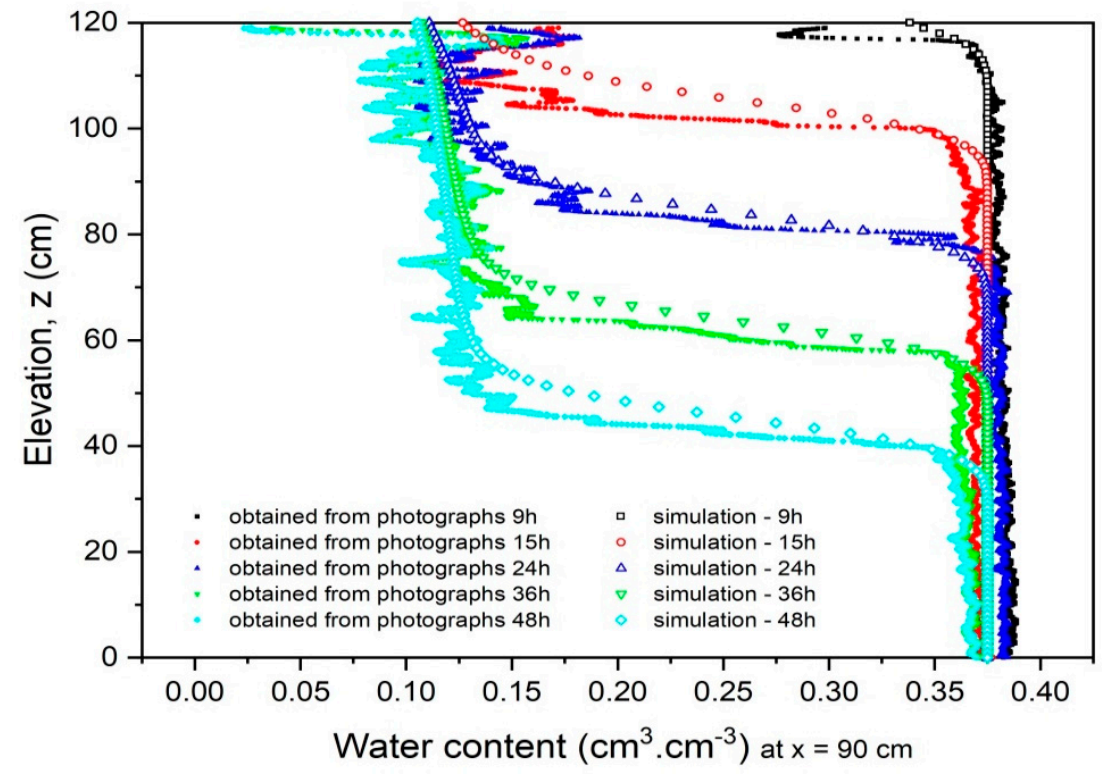

Figure 9. Water content profiles in the middle of the flow tank $(x=90 \mathrm{~cm})$ simulated (open symbols) and obtained with photometric procedure (solid symbols) at different times of the first drainage-imbibition experiment (black squares $=9 \mathrm{~h}$; red circles $=15 \mathrm{~h}$; blue triangles $=24 \mathrm{~h}$; green triangles $=36 \mathrm{~h}$; cyan diamonds $=48 \mathrm{~h}$ ). 


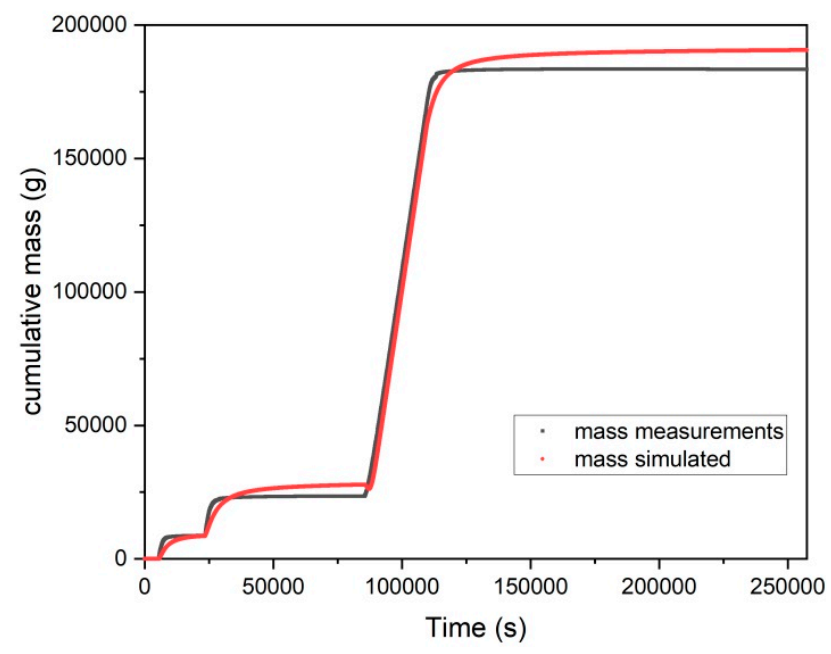

Figure 10. Evolution of the cumulative mass of water leaving the tank during the drainage and rainfall part of the 2nd experiment; the red line depicts the results of simulation and the black line represents the measurements.

\subsection{Second Experiment: Drainage-Rainfall Infiltration-Drainage-Imbibition Cycle}

The second experiment was carried out as follows (cf. Table 1): 1) the flow tank was fully saturated and observed for 90 minutes; 2) then, the drainage phase was realized in two stages: the overflow outlets were moved downward by $50 \mathrm{~cm}$ and $48.5 \mathrm{~cm}$. An equilibrium interval of 5 hours was included between these two steps. 3) After an equilibrium time of 17 hours, a constant rainfall was applied to a central upper zone of about $60 \mathrm{~cm}$ for 7 hours. 4) A free drainage step and an equilibrium phase were carried out for 41 hours. 5) Finally, the imbibition phase was achieved in 3 stages with successive increases of the overflow outlets level: an increase of $48.5 \mathrm{~cm}$ was carried out, followed by a break of 5 hours, a second rise of $49 \mathrm{~cm}$ with a break of 1 hour and a final rise of $1 \mathrm{~cm}$ to reach the fully saturated state.

Concerning the rain simulation device, it was manually adjusted with an overall hourly injection rate of about 22.74 liters, and, despite the use of a filter at the pump inlet, we did not operate in a closed circuit to avoid clogging the injection nozzle. On the other hand, this setup allowed continuous monitoring of the cumulative mass of water flowing from the overflow outlets with a digital mass balance. For this second experiment, several soil material properties were compared (sim 1 to sim 4 provided in [23]) and the values corresponding to $\operatorname{sim} 4$ were adopted: $K_{S}=2.7410^{-2} \mathrm{~cm} \cdot \mathrm{s}^{-1}, \theta_{s}=0.376$, $\theta_{r}=0.088, \alpha=0.054 \mathrm{~cm}^{-1}, n=7.37$ and $S_{S}=1.10^{-10} \mathrm{~cm}^{-1}$. Due to the 2D nature of the flow, which may be explained with the simulation of rain on part of the porous medium at the surface of the tank, the choice of parameters had a greater impact on the numerical results.

Figure 10 displays the cumulative mass of water collected at the outlets of the overflow during the parts of the experiment composed of the two-step drainage and the rainfall and stabilization periods. The comparison between measurements and simulated results shows very good correlation and the relative error in the volume of water injected during rainfall does not exceed $3 \%$.

As shown in Figure 12, our methodology for image analysis works very well for creating water content maps in a more complex flow situation than drainage and imbibition. The simulation results presented at different times of the experiment are in close agreement with the water content maps. Even if the medium is homogeneous, and while the simulated maps are naturally very regular, the photographs make it possible to illustrate certain irregularities in the water flow that could be due to disparities in the compaction of the porous medium during filling. Compared to the results obtained with a small tank (L: $40 \mathrm{~cm} \times \mathrm{W}: 14 \mathrm{~cm}$ in [23]), Figure 12 illustrates the effectiveness of the method, which does not generate too many discrepancies in working with a larger tank; it could be noticed that the mesh size of the picture $\left(1 \mathrm{~cm}^{2}\right)$ was not modified, even if this would have allowed 
the water content maps to be smoothed. The presence of the reinforcement bars on the experimental device cannot be completely removed during image processing, but the various steps make it possible to limit the impact of the shadows generated by the two projectors.

Time (s)

21600

85200

92400

93600
Photograph
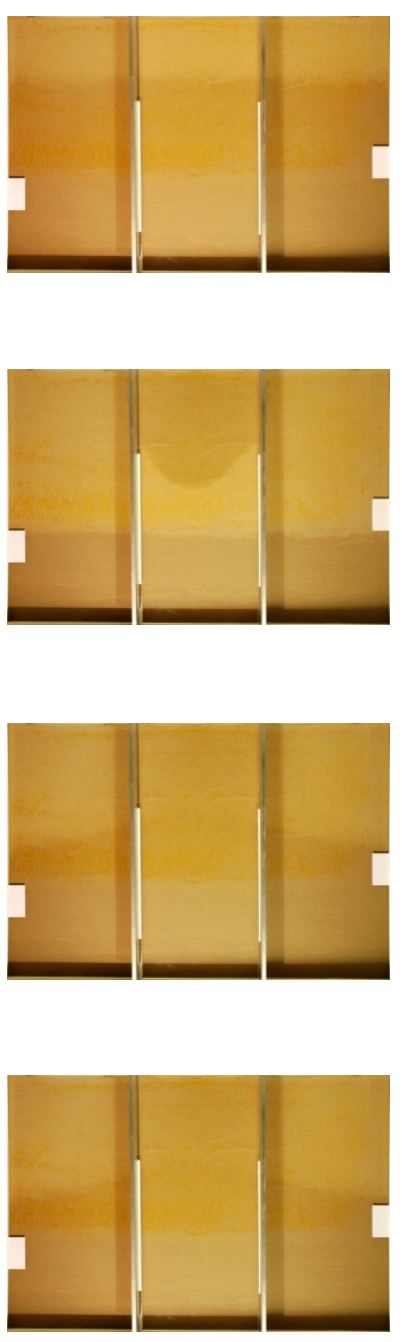

Map from numerical simulation
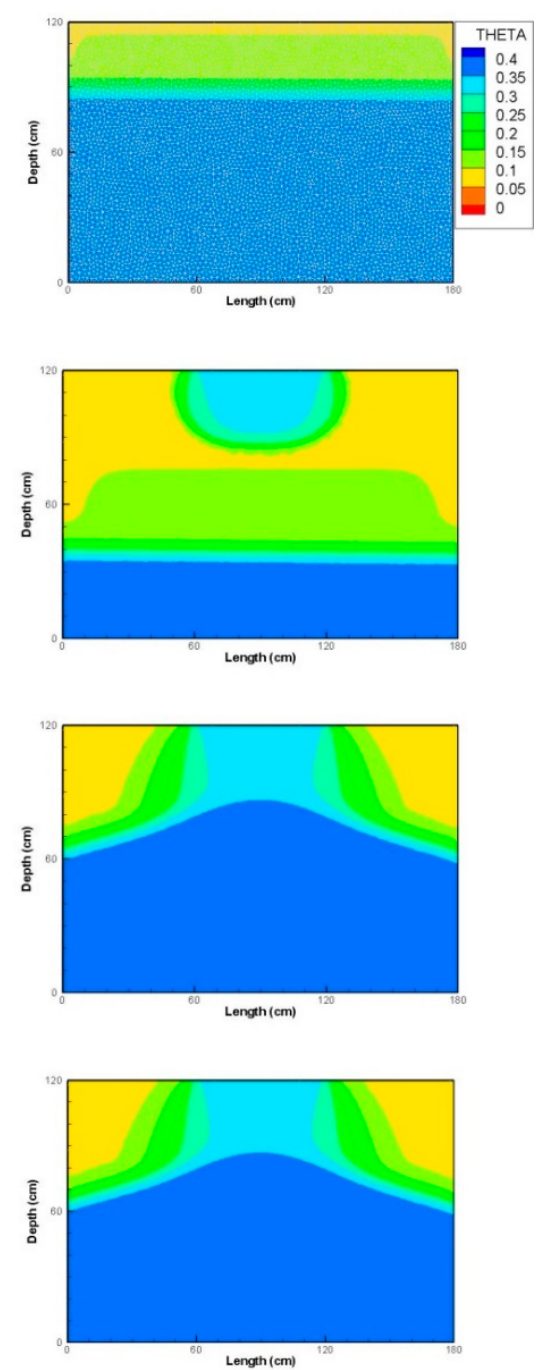

Figure 11. Cont. 
111600
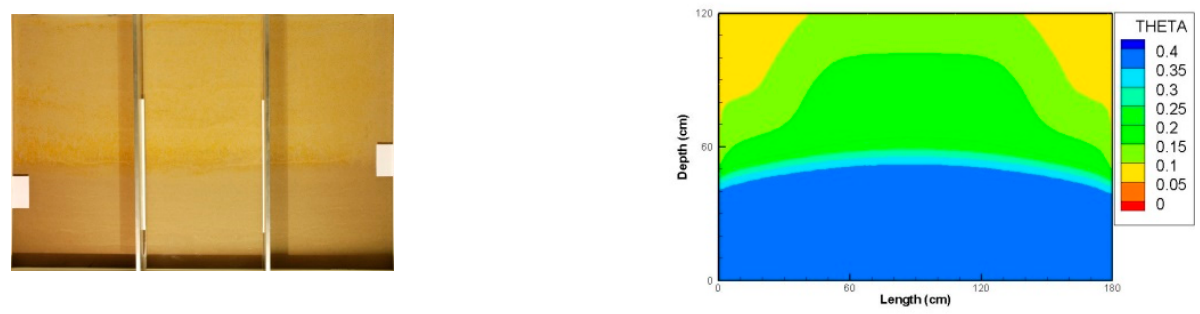

147600
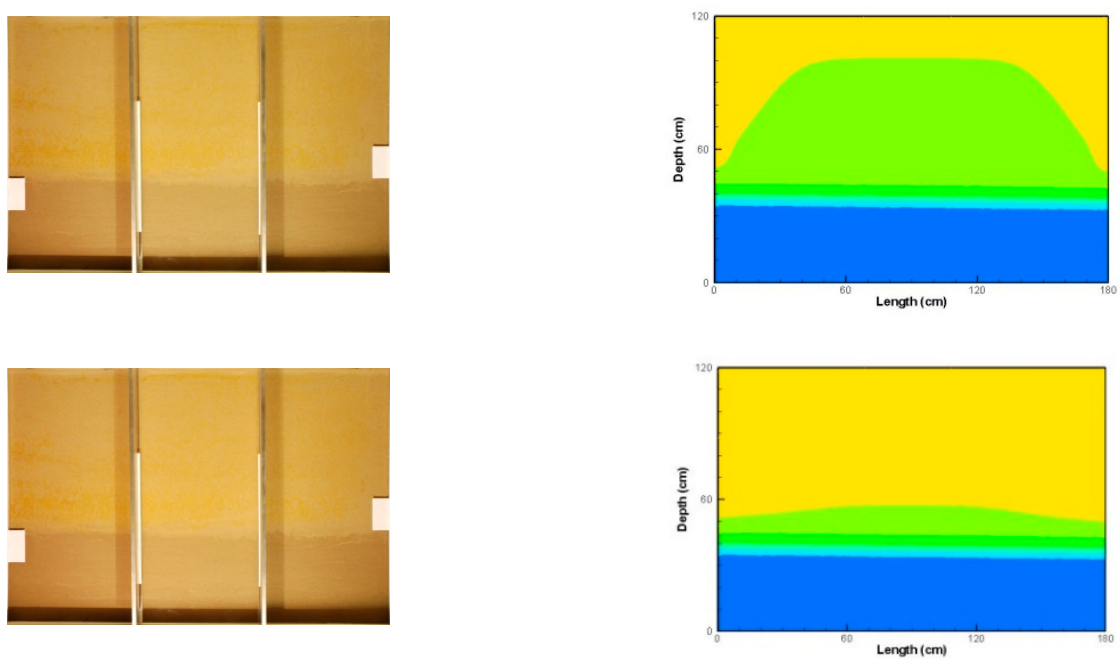

237600
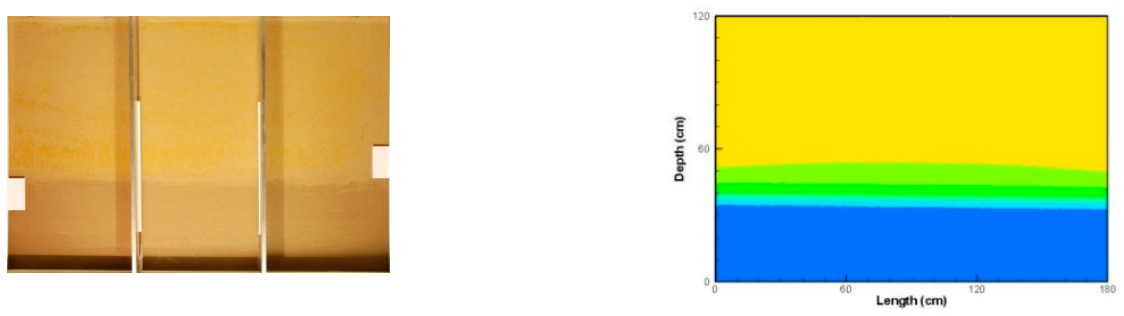

Figure 12. Cont. 
255600

273600

291600
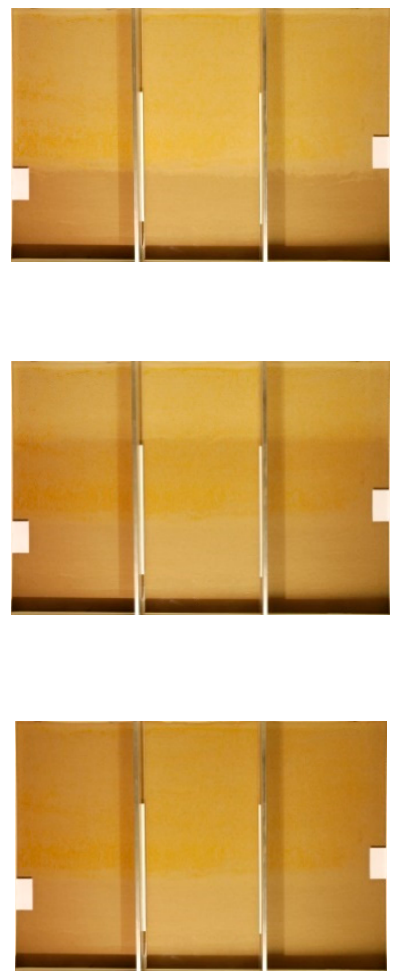
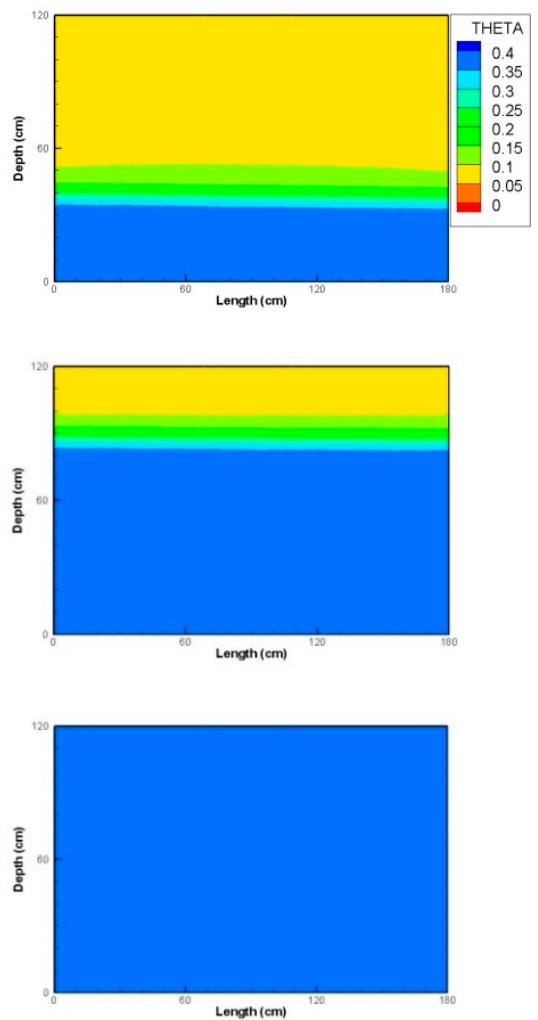

Figure 12. Results obtained for the second experiment including rainfall: presentation of the original photographs, maps resulting from image analysis method (right side) and numerical simulation (middle).

\section{Conclusions}

The purpose of the present study was to test the methodology proposed by Belfort et al. (2017) [23] in a more complex flow situation and a much larger experimental tank. Indeed, the internal dimensions of the flow chamber are $120 \mathrm{~cm} \times 180 \mathrm{~cm} \times 4 \mathrm{~cm}(\mathrm{~L} \times \mathrm{W} \times \mathrm{D})$, which corresponds to a viewing area 90 times larger than for the validation experiment [23]. As for the experimental conditions, in addition to the drainage and imbibition steps, a rain simulation was carried out on the central upper part of the tank, introducing true 2D flows.

First, we demonstrated the interest of the different steps of our methodology; mainly, normalization and then filtering according to a chosen radius. The calibration line was constructed according to a well-established protocol based on different drainage and imbibition levels. The confidence interval and error bars have been depicted to show the quality of the calibration. For the first experiment, the absolute and relative cumulative errors are very good, with global amplitude that does not exceed $8 \%$. The monitoring of the cumulative mass of water leaving (or entering the interior of) the flow chamber also shows a good match between measurements and results from the photometric method. For the vertical line located in the middle of the tank, the representation of simulated water content profiles and those obtained from the photos are very close together. In the second experiment carried out, which included a step of constant rainfall simulation, the cumulative mass was depicted to validate the numerical simulation compared to the measurement. The constant intensity of rain was clearly observed with a steady state occurring in the tank for both the experiment and the simulation. Then, water content maps obtained from image analysis methods and numerical models were depicted. It appears that the photometric method did not lead to regular maps compared to those resulting from simulations, and that instabilities were present. Nevertheless, the trend of the infiltration front, even during typical 2D flow related to rain infiltration, and the values of the water content in the main zones of the domain show great similitudes. Finally, the photometric method gave satisfactory 
results even in more complex conditions, and this article confirmed the potential of our previously published methodology. Again, we underline the interest of applying the methodology directly during the experiment because of the specific structure of the porous medium and environmental conditions.

Our previous study concluded by expressing our desire to develop a form of benchmark problem for unsaturated flow inspired by Vauclin's experiment [51]. With these two experiments, we can say that this objective has been achieved, since we have a wide range of water content and pressure measurements, as well as complete water content maps. Now, all this data could serve to develop and test parameter estimation methodologies directly in 2D without having to limit themselves to spot measurements. Ongoing work would also consider heterogeneous domain and/or more complex geometries.

Supplementary Materials: The following are available online at http://www.mdpi.com/2073-4441/11/11/2232/s1, Figure S1: Plans of the tank, Figure S2: Pictures of the tank, Video S1: 1st experiment, Video S2: 2nd experiment.

Author Contributions: B.B., S.W. and F.L. took part in the design conception and the experimental setup; they achieved measurements and developed the methodology of image analysis. M.F. was involved in the numerical developments. B.B. worked on the writing of this paper with the support of all the co-authors.

Funding: The study was partially financed by Strasbourg University and ENGEES; we acknowledge their scientific councils for their confidence.

Acknowledgments: We would like to express our sincere gratitude to our colleagues of the TrHyCo research team and especially Philippe Ackerer, Frederick Delay and Anis Younes. Also, a sincere thank you to our colleague, Rob SIMMONS, from IUT Louis Pasteur, for his diligent proofreading of the article.

Conflicts of Interest: The authors declare no conflict of interest.

\section{References}

1. Corwin, D.L.; Hopmans, J.; de Rooij, G.H. From Field- to Landscape-Scale Vadose Zone Processes: Scale Issues, Modeling, and Monitoring. Vadose Zone J. 2006, 5, 129-139. [CrossRef]

2. Fleckenstein, J.H.; Krause, S.; Hannah, D.M.; Boano, F. Groundwater-surface water interactions: New methods and models to improve understanding of processes and dynamics. Adv. Water Resour. 2010, 33, 1291-1295. [CrossRef]

3. Harter, T.; Hopmans, J.W. Role of vadose-zone flow processes in regional-scale hydrology: Review, opportunities and challenges. In Unsaturated-Zone Modelling: Progress, Challenges and Applications; Feddes, R.A., de Rooij, G.H., van Dam, J.C., Eds.; Springer: Dordrecht, The Netherlands, 2004; Volume 8, pp. 179-208.

4. Sophocleous, M. Interactions between groundwater and surface water: The state of the science. Hydrogeol. J. 2002, 10, 52-67. [CrossRef]

5. Or, D.; Smets, B.F.; Wraith, J.M.; Dechesne, A.; Friedman, S.P. Physical constraints affecting bacterial habitats and activity in unsaturated porous media-A review. Adv. Water Resour. 2007, 30, 1505-1527. [CrossRef]

6. Rivett, M.O.; Wealthall, G.P.; Dearden, R.A.; McAlary, T.A. Review of unsaturated-zone transport and attenuation of volatile organic compound (VOC) plumes leached from shallow source zones. J. Contam. Hydrol. 2011, 123, 130-156. [CrossRef] [PubMed]

7. Leong, E.C.; Rahardjo, H. Review of Soil-Water Characteristic Curve Equations. J. Geotech. Geoenviron. 1997, 123, 1106-1117. [CrossRef]

8. Malaya, C.; Sreedeep, S. Critical Review on the Parameters Influencing Soil-Water Characteristic Curve. J. Irrig. Drain. Eng. 2012, 138, 55-62. [CrossRef]

9. Steefel, C.I.; Appelo, C.A.J.; Arora, B.; Jacques, D.; Kalbacher, T.; Kolditz, O.; Lagneau, V.; Lichtner, P.C.; Mayer, K.U.; Meeussen, J.C.L.; et al. Reactive transport codes for subsurface environmental simulation. Computat. Geosci. 2015, 19, 445-478. [CrossRef]

10. Gargiulo, G.; Bradford, S.A.; Simunek, J.; Ustohal, P.; Vereecken, H.; Klumpp, E. Bacteria Transport and Deposition under Unsaturated Flow Conditions: The Role of Water Content and Bacteria Surface Hydrophobicity. Vadose Zone J. 2008, 7, 406-419. [CrossRef]

11. Dobriyal, P.; Qureshi, A.; Badola, R.; Hussain, S.A. A review of the methods available for estimating soil moisture and its implications for water resource management. J. Hydrol. 2012, 458-459, 110-117. [CrossRef] 
12. Ochsner, T.E.; Cosh, M.H.; Cuenca, R.H.; Dorigo, W.A.; Draper, C.S.; Hagimoto, Y.; Kerr, Y.H.; Njoku, E.G.; Small, E.E.; Zreda, M.; et al. State of the Art in Large-Scale Soil Moisture Monitoring. Soil Sci. Soc. Am. J. 2013, 77, 1888-1919. [CrossRef]

13. Robinson, D.A.; Campbell, C.S.; Hopmans, J.W.; Hornbuckle, B.K.; Jones, S.B.; Knight, R.; Ogden, F.; Selker, J.; Wendroth, O. Soil Moisture Measurement for Ecological and Hydrological Watershed-Scale Observatories: A Review. Vadose Zone J. 2008, 7, 358-389. [CrossRef]

14. Romano, N. Soil moisture at local scale: Measurements and simulations. J. Hydrol. 2014, 516, 6-20. [CrossRef]

15. Susha Lekshmi, S.L.; Singh, D.N.; Shojaei Baghini, M. A critical review of soil moisture measurement. Measurement 2014, 54, 92-105.

16. Vereecken, H.; Huisman, J.A.; Bogena, H.; Vanderborght, J.; Vrugt, J.A.; Hopmans, J.W. On the value of soil moisture measurements in vadose zone hydrology: A review. Water Resour. Res. 2008, 44. [CrossRef]

17. Duygu, B.M.; Akyürek, Z. Using Cosmic-Ray Neutron Probes in Validating Satellite Soil Moisture Products and Land Surface Models. Water 2019, 11, 1362. [CrossRef]

18. Zhou, L.; Yu, D.; Wang, Z.; Wang, X. Soil Water Content Estimation Using High-Frequency Ground Penetrating Radar. Water 2019, 11, 1036. [CrossRef]

19. Blonquist, J.M.; Jones, S.B.; Robinson, D.A. Standardizing Characterization of Electromagnetic Water Content Sensors. Vadose Zone J. 2005, 4, 1059-1069. [CrossRef]

20. Jones, S.B.; Blonquist, J.M., Jr.; Robinson, D.A.; Rasmussen, V.P.; Or, D. Standardizing Characterization of Electromagnetic Water Content Sensors: Part 1. Methodology. Vadose Zone J. 2005, 4, 1048-1058. [CrossRef]

21. Robinson, D.A.; Gardner, C.M.K.; Cooper, J.D. Measurement of relative permittivity in sandy soils using TDR, capacitance and theta probes: Comparison, including the effects of bulk soil electrical conductivity. J. Hydrol. 1999, 223, 198-211. [CrossRef]

22. Vaz, C.M.P.; Jones, S.; Meding, M.; Tuller, M. Evaluation of Standard Calibration Functions for Eight Electromagnetic Soil Moisture Sensors. Vadose Zone J. 2013, 12. [CrossRef]

23. Belfort, B.; Weill, S.; Lehmann, F. Image analysis method for the measurement of water saturation in a two-dimensional experimental flow tank. J. Hydrol. 2017, 550, 343-354. [CrossRef]

24. Oostrom, M.; Dane, J.H.; Wietsma, T.W. A Review of Multidimensional, Multifluid, Intermediate-Scale Experiments: Flow Behavior, Saturation Imaging, and Tracer Detection and Quantification. Vadose Zone J. 2007, 6, 610-637. [CrossRef]

25. Goswami, R.R.; Clement, T.P. Laboratory-scale investigation of saltwater intrusion dynamics. Water Resour. Res. 2007, 43. [CrossRef]

26. Konz, M.; Ackerer, P.; Meier, E.; Huggenberger, P.; Zechner, E.; Gechter, D. On the measurement of solute concentrations in 2-D flow tank experiments. Hydrol. Earth Syst. Sci. 2008, 12, 727-738. [CrossRef]

27. Konz, M.; Ackerer, P.; Huggenberger, P.; Veit, C. Comparison of light transmission and reflection techniques to determine concentrations in flow tank experiments. Exp. Fluids 2009, 47, 85-93. [CrossRef]

28. Konz, M.; Younes, A.; Ackerer, P.; Fahs, M.; Huggenberger, P.; Zechner, E. Variable-density flow in heterogeneous porous media - Laboratory experiments and numerical simulations. J. Contam. Hydrol. 2009, 108, 168-175. [CrossRef]

29. McNeil, J.D.; Oldenborger, G.A.; Schincariol, R.A. Quantitative imaging of contaminant distributions in heterogeneous porous media laboratory experiments. J. Contam. Hydrol. 2006, 84, 36-54. [CrossRef]

30. Oostrom, M.; Hayworth, J.S.; Dane, J.H.; Güven, O. Behavior of dense aqueous phase leachate plumes in homogeneous porous media. Water Resour. Res. 1992, 28, 2123-2134. [CrossRef]

31. Oostrom, M.; Dane, J.H.; Güven, O.; Hayworth, J.S. Experimental investigation of dense solute plumes in an unconfined aquifer model. Water Resour. Res. 1992, 28, 2315-2326. [CrossRef]

32. Rahman, M.A.; Jose, S.C.; Nowak, W.; Cirpka, O.A. Experiments on vertical transverse mixing in a large-scale heterogeneous model aquifer. J. Contam. Hydrol. 2005, 80, 130-148. [CrossRef] [PubMed]

33. Schincariol, R.A.; Schwartz, F.W. An experimental investigation of variable density flow and mixing in homogeneous and heterogeneous media. Water Resour. Res. 1990, 26, 2317-2329. [CrossRef]

34. Schincariol, R.A.; Herderick, E.E.; Schwartz, F.W. On the application of image analysis to determine concentration distributions in laboratory experiments. J. Contam. Hydrol. 1993, 12, 197-215. [CrossRef]

35. Simmons, C.T.; Pierini, M.L.; Hutson, J.L. Laboratory Investigation of Variable-Density Flow and Solute Transport in Unsaturated-Saturated Porous Media. Transp. Porous Media 2002, 47, 215-244. [CrossRef] 
36. Swartz, C.H.; Schwartz, F.W. An experimental study of mixing and instability development in variable-density systems. J. Contam. Hydrol. 1998, 34, 169-189. [CrossRef]

37. Van Geel, P.J.; Sykes, J.F. Laboratory and model simulations of a LNAPL spill in a variably-saturated sand, 1. Laboratory experiment and image analysis techniques. J. Contam. Hydrol. 1994, 17, 1-25. [CrossRef]

38. Wildenschild, D.; Jensen, K.H. Laboratory investigations of effective flow behavior in unsaturated heterogeneous sands. Water Resour. Res. 1999, 35, 17-27. [CrossRef]

39. Hoa, N.T. A new method allowing the measurement of rapid variations of the water content in sandy porous media. Water Resour. Res. 1981, 17, 41-48. [CrossRef]

40. Persson, M. Estimating Surface Soil Moisture from Soil Color Using Image Analysis. Vadose Zone J. 2005, 4, 1119-1122. [CrossRef]

41. Yoshimoto, N.; Orense, R.P.; Tanabe, F.; Kikkawa, N.; Hyodo, M.; Nakata, Y. Measurement of degree of saturation on model ground by digital image processing. Soils Found. 2011, 51, 167-177. [CrossRef]

42. Cremer, C.J.M.; Schuetz, C.; Neuweiler, I.; Lehmann, P.; Lehmann, E.H. Unstable Infiltration Experiments in Dry Porous Media. Vadose Zone J. 2017, 16. [CrossRef]

43. Conrad, S.H.; Glass, R.J.; Peplinski, W.J. Bench-scale visualization of DNAPL remediation processes in analog heterogeneous aquifers: Surfactant floods and in situ oxidation using permanganate. J. Contam. Hydrol. 2002, 58, 13-49. [CrossRef]

44. Gerhard, J.I.; Kueper, B.H. Capillary pressure characteristics necessary for simulating DNAPL infiltration, redistribution, and immobilization in saturated porous media. Water Resour. Res. 2003, 39. [CrossRef]

45. Abdul, A.S.; Gillham, R.W. Laboratory Studies of the Effects of the Capillary Fringe on Streamflow Generation. Water Resour. Res. 1984, 20, 691-698. [CrossRef]

46. Abdul, A.S.; Gillham, R.W. Field studies of the effects of the capillary fringe on streamflow generation. J. Hydrol. 1989, 112, 1-18. [CrossRef]

47. Hills, R.G.; Wierenga, P.J.; Hudson, D.B.; Kirkland, M.R. The Second Las Cruces Trench Experiment: Experimental Results and Two-Dimensional Flow Predictions. Water Resour. Res. 1991, 27, 2707-2718. [CrossRef]

48. Stauffer, F.; Dracos, T. Experimental and numerical study of water and solute infiltration in layered porous media. J. Hydrol. 1986, 84, 9-34. [CrossRef]

49. Stephens, D.B.; Heermann, S. Dependence of anisotropy on saturation in a stratified sand. Water Resour. Res. 1988, 24, 770-778. [CrossRef]

50. Tidwell, V.C.; Glass, R.J. X ray and visible light transmission for laboratory measurement of two-dimensional saturation fields in thin-slab systems. Water Resour. Res. 1994, 30, 2873-2882. [CrossRef]

51. Vauclin, M.; Khanji, D.; Vachaud, G. Experimental and numerical study of a transient, two-dimensional unsaturated-saturated water table recharge problem. Water Resour. Res. 1979, 15, 1089-1101. [CrossRef]

52. Yeh, T.-C.J.; Harvey, D.J. Effective unsaturated hydraulic conductivity of layered sands. Water Resour. Res. 1990, 26, 1271-1279. [CrossRef]

53. Beydoun, H.; Lehmann, F. Expériences de drainage et estimation de paramètres en milieu poreux non saturé. Comptes Rendus Geosci. 2006, 338, 180-187. [CrossRef]

54. DiCarlo, D.A. Stability of gravity-driven multiphase flow in porous media: 40 Years of advancements. Water Resour. Res. 2013, 49, 4531-4544. [CrossRef]

55. Hincapié, I.; Germann, P. Gravity-Driven Viscous Flow in Sand Boxes Assessed with Neutron Radiography. Vadose Zone J. 2009, 8, 891-901. [CrossRef]

56. Pfletschinger, H.; Engelhardt, I.; Piepenbrink, M.; Königer, F.; Schuhmann, R.; Kallioras, A.; Schüth, C. Soil column experiments to quantify vadose zone water fluxes in arid settings. Environ. Earth Sci. 2012, 65, 1523-1533. [CrossRef]

57. Sililo, O.T.N.; Tellam, J.H. Fingering in Unsaturated Zone Flow: A Qualitative Review with Laboratory Experiments on Heterogeneous Systems. Groundwater 2000, 38, 864-871. [CrossRef]

58. Noh, S.J.; An, H.; Kim, S.; Kim, H. Simulation of soil moisture on a hillslope using multiple hydrologic models in comparison to field measurements. J. Hydrol. 2015, 523, 342-355. [CrossRef]

59. Vanderborght, J.; Kasteel, R.; Herbst, M.; Javaux, M.; Thiéry, D.; Vanclooster, M.; Mouvet, C.; Vereecken, H. A Set of Analytical Benchmarks to Test Numerical Models of Flow and Transport in Soils. Vadose Zone J. 2005, 4, 206-221. [CrossRef] 
60. Gaskin, G.J.; Miller, J.D. Measurement of Soil Water Content Using a Simplified Impedance Measuring Technique. J. Agric. Eng. Res. 1996, 63, 153-159. [CrossRef]

61. Van Genuchten, M.T. A Closed-form Equation for Predicting the Hydraulic Conductivity of Unsaturated Soils1. Soil Sci. Soc. Am. J. 1980, 44, 892-898. [CrossRef]

62. Belfort, B.; Younes, A.; Fahs, M.; Lehmann, F. On equivalent hydraulic conductivity for oscillation-free solutions of Richard's equation. J. Hydrol. 2013, 505, 202-217. [CrossRef]

63. Fahs, M.; Younes, A.; Lehmann, F. An easy and efficient combination of the Mixed Finite Element Method and the Method of Lines for the resolution of Richards' Equation. Environ. Modell. Softw. 2009, 24, 1122-1126. [CrossRef]

64. Russ, J.C. The Image Processing Handbook; CRC Press: Boca Raton, FL, USA, 2011.

65. Gimmi, T.; Ursino, N. Mapping Material Distribution in a Heterogeneous Sand Tank by Image Analysis. Soil Sci. Soc. Am. J. 2004, 68, 1508-1514. [CrossRef]

66. Almhdie, A.; Rozenbaum, O.; Lespessailles, E.; Jennane, R. Image processing for the non-destructive characterization of porous media. Application to limestones and trabecular bones. Math. Comput. Simul. 2014, 99, 82-94. [CrossRef]

67. Yu, Z.; Schwartz, F.W. Determining concentration fields of tracer plumes for layered porous media in flow-tank experiments. Hydrogeol. J. 1999, 7, 236-240. [CrossRef]

68. Kaestner, A.; Lehmann, E.; Stampanoni, M. Imaging and image processing in porous media research. Adv. Water Resour. 2008, 31, 1174-1187. [CrossRef]

(C) 2019 by the authors. Licensee MDPI, Basel, Switzerland. This article is an open access article distributed under the terms and conditions of the Creative Commons Attribution (CC BY) license (http://creativecommons.org/licenses/by/4.0/). 